\title{
MCNP Simulation of Discrete Gamma-ray Spectra for PGNAA Applications
}

\section{IEEE Nuclear Science Symposium and Medical Imaging Conference}

\author{
E. H. Seabury, C. J. Wharton, A. J. Caffrey
}

The INL is a

U.S. Department of Energy

National Laboratory

operated by

Battelle Energy Alliance

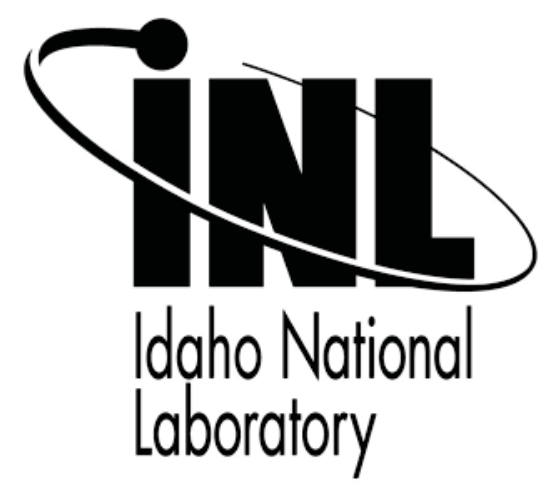

This is a preprint of a paper intended for publication in a journal or proceedings. Since changes may be made before publication, this preprint should not be cited or reproduced without permission of the author. This document was prepared as an account of work sponsored by an agency of the United States Government. Neither the United States Government nor any agency thereof, or any of their employees, makes any warranty, expressed or implied, or assumes any legal liability or responsibility for any third party's use, or the results of such use, of any information, apparatus, product or process disclosed in this report, or represents that its use by such third party would not infringe privately owned rights. The views expressed in this paper are not necessarily those of the United States Government or the sponsoring agency. 



\title{
MCNP Simulation of Discrete Gamma-ray Spectra for PGNAA Applications
}

\author{
E. H. Seabury, C. J. Wharton, and A. J. Caffrey, Senior Member, IEEE
}

\begin{abstract}
Prompt Gamma Neutron Activation Analysis (PGNAA) systems, such as Idaho National Laboratory's PINS system [1], are used by the U.S. Army to identify chemical warfare materiel (CWM) and explosives in recovered munitions. The wide variety of fill chemicals and assessment conditions for these munitions makes Monte Carlo modeling of the gamma spectra attractive in order to assess the impact of these variations on identification algorithms as have recent improvements to the prompt gamma production in the nuclear data libraries for low$\mathrm{Z}$ chemical elements. The availability of High Performance Computing (HPC) systems makes these simulations more rapid than laboratory measurements, and can be very useful provided the codes and associated data libraries accurately reproduce the laboratory measurements. We present here a comparison of simulation results using the MCNP6 code [2] and the ENDF/BVII libraries with laboratory measurements using two different neutron sources, a californium-252 source and a deuteriumdeuterium (DD) neutron generator.
\end{abstract}

\section{INTRODUCTION}

Prompt Gamma Neutron Activation (PGNAA) systems use $P$ the neutron-induced gamma-ray spectra from test objects in order to identify their compositions. The U.S. Army in particular uses these systems to identify the contents of fieldrecovered munitions in order to determine the presence of chemical warfare materiel (CWM) or explosives. These fieldrecovered munitions can have a variety of different fills, including experimental fills, have a large range of sizes, and be assessed in different field conditions. All these variations can have a significant effect on the neutron-induced gammaray spectrum and therefore a large impact on automatic fill identification algorithms. In order to develop robust identification algorithms, parametric studies of the effects of munition size, fill composition, and assessment conditions are very useful but time-consuming and expensive in the laboratory. Monte Carlo modeling of the system response to these variations is a very attractive alternative, provided the modeling accurately reflects real gamma spectra and can be performed quickly and inexpensively when compared to experiment.

At Idaho National Laboratory we have used the Monte Carlo N-Particle (MCNP6) code [2] to calculate the response of the Portable Isotopic Neutron Spectroscopy (PINS) system

Manuscript received November 23, 2015. This work was supported by the Joint Project Manager for Elimination, Joint Program Executive Office for Chemical and Biological Defense, and by the Recovered Chemical Materiel Directorate, U.S. Army Chemical Materials Activity, under U.S. Department of Energy Field Office Idaho contract number DE-AC07-05ID14517.

E. H. Seabury is with Idaho National Laboratory, Idaho Falls, ID 83415 USA (telephone: 208-526-5303, e-mail: Edward.seabury@inl.gov.

C.J. Wharton and A.J. Caffrey are also with Idaho National Laboratory. to a number of simulated chemical warfare munitions as well as performed laboratory measurements with the system. Two versions of PINS system were used; one excited the test object with neutrons from a ${ }^{252} \mathrm{Cf}$ source and one with neutrons from a portable deuterium-deuterium (DD) neutron generator. The sets of measurements and simulations with the two different neutron sources provided experimental data for development of automatic fill identification algorithms as well as providing a good test of the agreement between the MCNP calculations and experiment.

\section{EXPERIMENTAL \& MODELING ARRANGEMENT}

\section{A. PINS Systems}

Two of INL's PINS systems were modeled and used in the experiments. The first is the miniPINS or PINS-2 system. This system uses a $5.0 \mu \mathrm{g}$ isotopic ${ }^{252} \mathrm{Cf}$ neutron source and a liquid-nitrogen-cooled high-purity germanium (HPGe) detector. The neutron source emits approximately $1.0 \times 10^{7}$ neutrons/second. A schematic of the PINS-2 system is shown in Fig. 1 below.

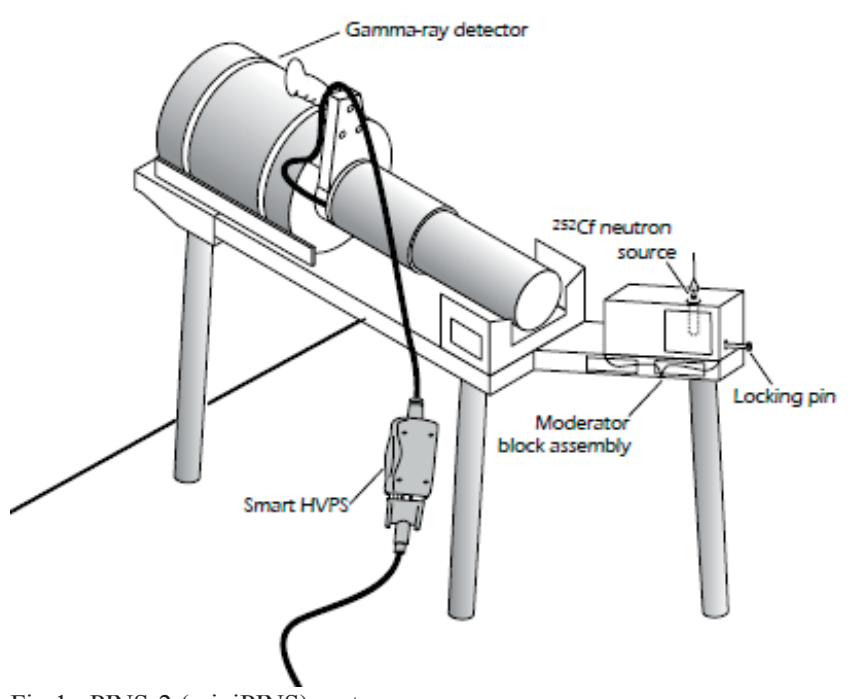

Fig 1. PINS-2 (miniPINS) system

The second system used was a PINS-3 DD system. This system uses a mechanically-cooled Ortec Transpec instead of a liquid-nitrogen-cooled HPGe detector. The neutron source for this system is a Thermo-Scientific P-385 DD neutron generator, emitting approximately $5.0 \times 10^{6}$ neutron/second. A schematic of the PINS-3 DD system is shown in Fig. 2.

For each of the two systems, a sample was placed in position in front of the detector and data was collected for 3,000 live seconds. 


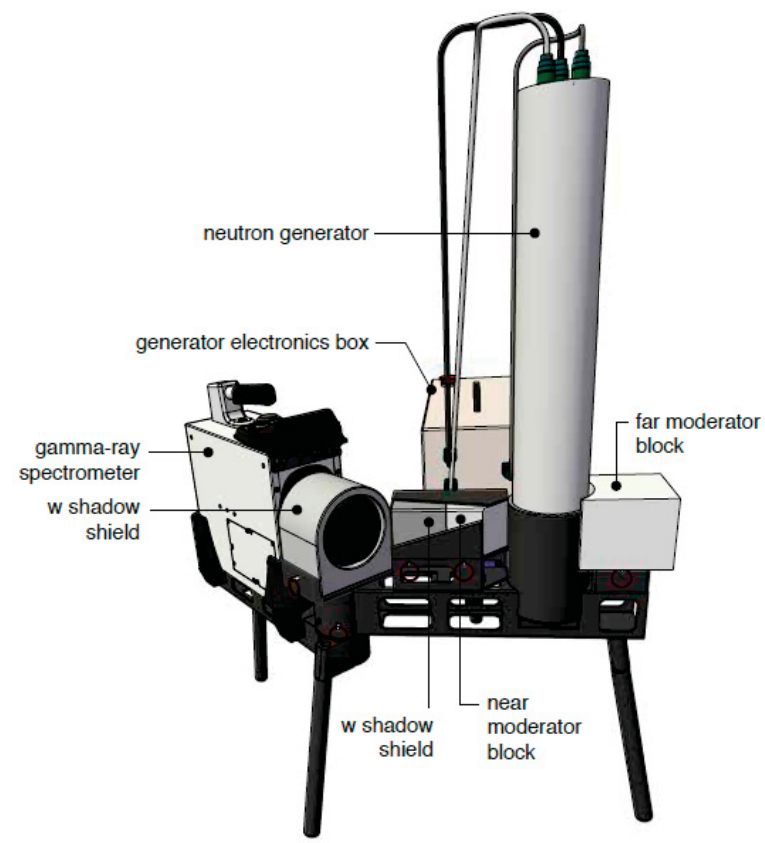

Fig 2. PINS-3 DD system

\section{B. Test Objects}

Measurements were made on a number of test objects. These test objects consisted of teflon containers of chemicals that were formulated to have the same or similar elemental composition as chemical warfare materiel (CWM) or obscuring smokes. Table 1 below shows the composition of the chemicals as well as the NATO designation of the CWM that they are intended to simulate.

\section{TABLE I. SIMULANT CHEMICALS}

\begin{tabular}{ll} 
Agent & Composition \\
\hline HD & $80 \%$ polyvinylchloride, $20 \%$ sulfur \\
L & $57 \%$ hexachloroethane, $36 \%$ As, $7 \%$ polyethylene \\
BR2 & $24.5 \%$ hexachloroethane, $30.8 \%$ As, \\
& $21.5 \%$ polyethylene, $23.2 \%$ graphite \\
WL & $35.4 \%$ hexachloroethane, $20 \%$ As, \\
& $27 \%$ polyethylene, $10 \%$ sulfur, $7.6 \%$ graphite \\
CG & $61 \%$ oxalyl chloride, $39 \%$ carbon tetrachloride \\
CK & $100 \%$ cyanuric chloride \\
CNS & $72 \%$ hexachloroethane, $28 \%$ succinimide \\
CNB & $45 \%$ benzene, $45 \%$ carbon tetrachloride, \\
& $10 \%$ chloroacetophenone \\
CN & $100 \%$ chloroacetophenone \\
VX & $35 \%$ trimethylphosphine oxide, $42 \%$ nylon, \\
& $12 \%$ sulfur, $11 \%$ polyethylene \\
HC & $16 \%$ alumina, $79 \%$ zinc chloride, $5 \%$ graphite \\
KJ & $100 \%$ stannic chloride \\
\hline
\end{tabular}

The teflon containers of chemicals were placed inside steel containers in order to simulate munitions. One container mimicked a 4.2-inch mortar projectile, and the other a 155 $\mathrm{mm}$ artillery projectile.

\section{Modeling Procedure}

All the modeling was performed using the MCNP6 (ver. 1.0) code and the ENDF/B-VII.1 libraries that are distributed with the code. The geometries for the models included the HPGe detector, shadow shielding and moderator blocks, the test object, and the ${ }^{252} \mathrm{Cf}$ or neutron generator as appropriate.

The simulations were performed on INL's High Performance Computing Enclave in a two-step process. The first step consisted of calculating the photon flux (F2 tally) on the detector face as a result of the neutron interactions with the materials of the model. The second step was a calculation of the detector response (F8 tally) to the photon flux produced in the first step. Simulations were performed for all the materials listed in Table 1 for both the PINS-2 and PINS-3 DD systems.

\section{RESULTS}

The goal of PGNAA measurements of field-recovered munitions is to identify the contents of the munition, and generally not to quantify the amount of material inside the munition. Given that, we are generally more concerned with the relative intensities of certain gamma-ray peaks compared with others rather than their absolute intensities. Comparison between the calculated and measured spectra therefore relies heavily on ratios of peak areas.

A visual comparison of a calculated versus a measured spectrum can be seen in Fig. 3. This particular example is that of the 4.2-inch container with simulated mustard gas (HD). As can be seen in the Fig., the two spectra contain many of the same gamma-ray peaks. The key peaks of interest in these spectra are those from thermal neutron capture on chlorine at 1951 and $1959 \mathrm{keV}$ and from inelastic neutron scattering on sulfur at $2230 \mathrm{keV}$ and chlorine at $1763 \mathrm{keV}$. The detection of these peaks and the values of their ratios are used to determine whether a munition contains mustard gas.
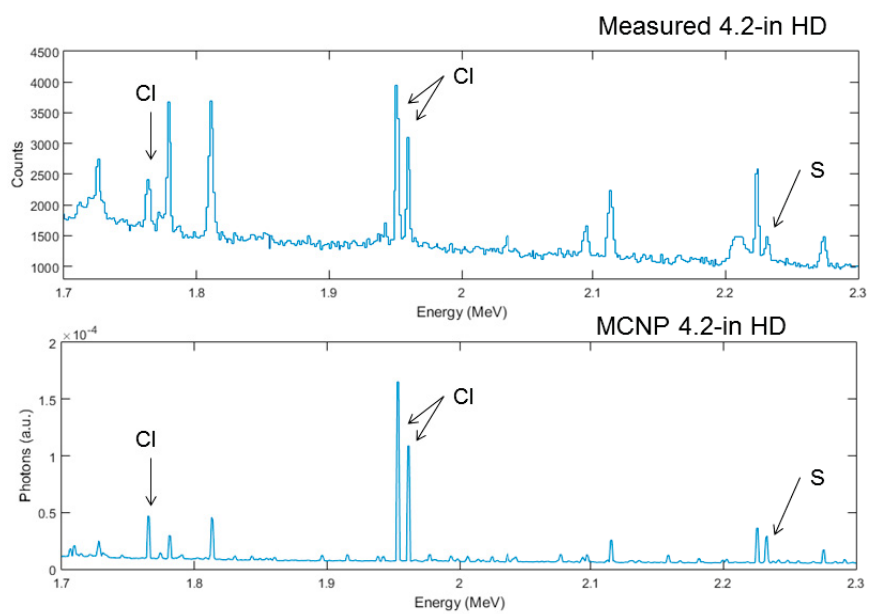

Figure 3 Measured vs simulated HD spectra 
The measured and calculated spectra were analyzed to determine the areas of peaks used to identify CWM. A list of these peaks is shown in Table 2. A few of these peaks are not included in the ENDF/B-VII.1 library and therefore cannot be used to compare modeling with measurements.

TABLE II. KEY ELEMENT PEAKS

\begin{tabular}{lll} 
Element & \multicolumn{1}{c}{$\begin{array}{c}\text { Thermal Capture Peaks } \\
(\mathrm{keV})\end{array}$} & $\begin{array}{c}\text { Inelastic Scattering Peaks } \\
(\mathrm{keV})\end{array}$ \\
\hline $\mathrm{Cl}$ & $1165,1951,1959,6111$ & 1763 \\
$\mathrm{H}$ & 2223 & \\
$\mathrm{~N}$ & 5269,10829 & 5108 \\
$\mathrm{P}$ & $3900^{*}$ & 1266,2233 \\
$\mathrm{~S}$ & $2379^{*}, 5421^{*}$ & 2230 \\
$\mathrm{As}$ & & 265,279 \\
$\mathrm{Zn}$ & & 992,1077 \\
$\mathrm{Sn}$ & & $1171^{*}, 1230^{*}$
\end{tabular}

*Not included in ENDF/B-VII.1 Libraries

\section{ACKNOWLEDGMENT}

We'd like to thank the administrators of INL's HPC environment for their aid in performing calculations on these systems and our INL colleagues Ann Egger, Ken Krebs, and John Zabriskie for their work on the PINS systems hardware and software. We'd also like to thank our PNNL colleague Kim Burns and our LLNL colleague Brad Sleaford for their helpful discussions about modeling the response of chemical warfare materiel to neutrons.

\section{REFERENCES}

[1] A.J. Caffrey, J.D. Cole, R.J. Gehrke, and R.C. Greenwood, "Chemical Warfare Agent and High Explosive Identification by Spectroscopy of Neutron-induced Gamma-Rays", IEEE Transactions on Nuclear Science, 39, (1992), pp 1422-1426.

[2] J.T. Goorley, et al., "Initial MCNP6 Release Overview - MCNP6 version 1.0", Los Alamos National Laboratory Report, LA-UR-1322934 (2013)

[3] B. Sleaford, priv. comm, (2013).

\section{CONCLUSIONS}

A few key gamma-ray peaks are not available in the ENDF/B-VII.1 libraries including capture gamma-ray peaks from ${ }^{32} \mathrm{~S}$ and ${ }^{31} \mathrm{P}$ and neutron inelastic scattering peaks from ${ }^{120} \mathrm{Sn}$. Alternate libraries can be used for the neutron capture peaks in particular[3], but having fully evaluated and complete libraries distributed with the code would be very valuable for PGNAA applications.

Aside from a few missing gamma-ray lines, the calculated spectra show all the key gamma-ray peaks that are used in the PINS fill identification algorithms. Ratios of the areas of these peaks are critical in the identification algorithms and there is some disagreement between calculated and measured peak area ratios. All of the calculated chlorine inelastic-tocapture peak area ratios (Clic ratios) are higher than their measured counterparts for both the ${ }^{252} \mathrm{Cf}$ and DD neutron sources. This deviation appears strongest for those chemicals that are weakly moderating, i.e. contain no hydrogen.

Even though there is some discrepancy between calculation and measurement the overall trends of the elemental ratios was preserved when comparing the response of one chemical to another. This is very useful when trying to predict the response of the PINS systems to a new, previously unmeasured chemical.

Continuing work will include determining the source of discrepancies between measurement and calculation and extending the calculations and measurements to include the system responses from a deuterium-tritium (DT) $14 \mathrm{MeV}$ neutron source. 